\section{Quantifying Key Internal and External Yield-limiting Factors for Chinese Pear in Smallholder Dominant Areas}

\author{
Haoran Fu, Qingxu Ma, Zhengbo Ma, Yingzhao Hu, Fan Liu, \\ Kaijun Chen, Wankun Pan, Sheng Tang, Xin Zhang, and \\ Lianghuan Wu \\ Zhejiang Provincial Key Laboratory of Agricultural Resources and Environment, \\ College of Environmental and Resource Sciences, Zhejiang University, \\ Hangzhou 310058, China
}

Additional index words. best management practice, boundary line model, fertilizer nitrogen rate, scenario analysis

\begin{abstract}
Pear (Pyrus spp.) is the third-largest economic crop in China after apples (Malus pumila Mill.) and citrus (Citrus reticulata Blanco), and it is mainly cultivated by smallholders. Currently, the yield of Chinese pear ranks midlevel globally, with only 17.9 $\mathrm{t}_{\mathrm{ha}} \mathrm{h}^{-1} \cdot \mathrm{year}^{-1}$, which is lower than that of the United States $\left(36.0 \mathrm{t}^{-h^{-1}} \cdot \mathrm{year}^{-1}\right)$. However, the factors limiting pear production dominated by smallholders are unclear. We interviewed 75 smallholders about 18 yield-related indicators for pear-typical planting areas. The boundary line model was used to analyze the contribution of internal factors and dominant external factors affecting yield and to simulate strategies for increasing yield through the scenario analysis. The results showed that the average gap between the average and highest attainable yields for smallholders was $10.5 \mathrm{t} \cdot \mathrm{ha}^{-1} \cdot \mathrm{year}^{-1}$ in Luniao County. Among individual yield-limiting factors, chemical fertilizer nitrogen (N) input $(13.3 \%)$ was the most significant, followed by the soil-available $N$ content $(12.0 \%)$ and leaf magnesium content $(\mathbf{1 2 . 0 \%})$. Overall, the contribution of all soil factors $(42.7 \%)$ was the largest compared with the other factor categories. However, the contribution of internal factors could not be ignored and accounted for $\mathbf{2 5 . 3 \%}$ of the total. A scenario analysis showed that comprehensive strategies considering soil, management, and internal factors achieved the largest yield improvement $(14 \%)$, as did reducing the fertilizer application rate $(66 \%)$ compared with only using soil or leaf diagnosis methods. Therefore, integrated methods should be considered when developing pear orchard management measures and include soil, management, and internal factors.
\end{abstract}

Pear (Pyrus spp.) cultivation is among the primary sources of income for farmers in China (Zhu et al., 2017) and has a history spanning more than 3000 years (Song et al., 2014). The cultivation area for pear in China is 1.0 million ha, which is the largest in any country worldwide (FAO, 2019). However, the average yield is $17.9 \mathrm{t} \cdot \mathrm{ha}^{-1} \cdot \mathrm{year}^{-1}$, which is only one-third the average yield of the top ten pear-growing countries of the world, indicating that there is great potential for improvement (FAO, 2019). For example, the average yield in the United States is 36.0

Received for publication 16 July 2021. Accepted for publication 16 Aug. 2021.

Published online 15 October 2021

This research was financed by the Science and Technology Planning Project of Ningbo City, China $(202002 \mathrm{~N} 3106)$ and the university-enterprise cooperation project of Luniao County, China (2020330004002089).

H.F. and L.W. conceived and designed the study, analyzed data and drafted the manuscript; Z.M. Y.H., F.L., K.C., W.P., S.T., and X.Z. performed the experiments; Q.M. revised the manuscript.

L.W. is the corresponding author. E-mail: finm@zju.edu.cn.

This is an open access article distributed under the CC BY-NC-ND license (https://creativecommons. org/licenses/by-nc-nd/4.0/). pear yield gradually increases as the trees age from 1 to 10 years old because the trees can absorb nutrients over time (Liu et al., 2016). In addition, the tree leaves are very sensitive to surpluses or deficiencies in mineral nutrients, which have essential roles in structural components and energy transformation (Dar et al., 2015). The elements contained in leaves are directly related to yield and include N, phosphorus $(\mathrm{P})$, potassium $(\mathrm{K})$, calcium $(\mathrm{Ca})$, magnesium (Mg), and others (Awasthi et al., 1998; Babu and Yadav, 2005; Kumar et al., 2007).

Various methods have been applied to assess the effects of different indicators on yield, such as field trials (Gomand et al., 2018) and crop growth models (De MeloAbreu et al., 2015). However, these methods do not consider the actual production situation of farmers (Cao et al., 2019). The boundary line model is a more comprehensive method that has been widely applied to assess yieldlimiting factors of wheat (Cao et al., 2019; Li et al., 2020), maize (Chen et al., 2018), apple (Zhang et al., 2019a), mango (Zhang et al., 2019b), and other crops (Mahbubeh et al., 2021). However, these studies did not evaluate the effect of internal factors on yield.

Until now, the factors limiting the yield of Chinese pear are unclear. Using the boundary line model, this study aimed to 1) quantify the effects of internal factors on and identify the overall key limiting factors for pear yield at smallholder farms in China and 2) explore the best agronomy practice strategies for yield improvement.

\section{Materials and Methods}

Site description. The research site was in Luniao County (lat. $30^{\circ} 27^{\prime} \mathrm{N}-30^{\circ} 28^{\prime} \mathrm{N}$, long. $\left.119^{\circ} 43^{\prime} \mathrm{E}-119^{\circ} 46^{\prime} \mathrm{E}\right), \quad$ Zhejiang Province, which is a typical pear planting area of smallholders with 0.7 ha per capita arable area and more than 30 years of planting history. The mean annual temperature and precipitation are $16.0^{\circ} \mathrm{C}$ and $1350 \mathrm{~mm}$, respectively; these are typical climatic conditions for sand pear growth in south China. The major pear variety grown in this county is 'Cuiguan', a predominant cultivar of sand pear.

Data collection and processing. Data were collected and processed from 10 Aug. 2020 to 25 Jan. 2021. Seventy-five smallholders were randomly selected from the county's planting list; their basic information is shown in Table 1 . We investigated the yield, soil properties, farmer agronomy practices, tree age, tree density, and leaf nutrient content. The pear yield, tree density, tree age, and management practices were collected via a face-to-face questionnaire. Pear tree agronomy management mainly includes fertilization, insecticides and fungicides, pruning branches, pollination, flower thinning, and fruit thinning. Farmers use the same operations for pruning branches, thinning flowers, and thinning fruits; therefore, we chose the fertilization (mineral fertilizer $\mathrm{N}, \mathrm{P}_{2} \mathrm{O}_{5}$, and $\mathrm{K}_{2} \mathrm{O}$ input) and spraying situation (pest and disease control time) as the main management factors. None of the farmers thinned 
Table 1. Characteristics of the investigated smallholders.

\begin{tabular}{lrrr}
\hline Factors & \multicolumn{1}{c}{ Average } & Min. & Max. \\
\hline Farmer age $(\mathrm{yr})$ & $62.31 \pm 9.45$ & 36 & 82 \\
Years of education $(\mathrm{yr})$ & $7.43 \pm 2.71$ & 1 & 16 \\
\hline Data is average \pm SD. & & &
\end{tabular}

flowers and fruits twice; therefore, these factors were not considered during our analysis. Soil properties included soil organic matter, available $\mathrm{N}$, available $\mathrm{P}$, available $\mathrm{K}$, soluble $\mathrm{Ca}$, and soluble $\mathrm{Mg}$. In the leaf, we measured the total N, P, K, Ca, and Mg contents. Soil and leaf samples were collected from the farms during the pear harvest period (Fig. 1). The soil sample was a mixed sample of the 0 to $40-\mathrm{cm}$ layer from three plots collected from near the drip line of the vertical projection of the canopy, as described by $\mathrm{Wu}$ et al. (2010). Twenty leaves were collected from sites corresponding to the soil samples and taken from the middle of new shoots at the periphery of the trunk (five leaves in each of the four directions: south, east, north, and west).

Soil properties were analyzed using methods established by Bao (2000) as follows: the soil organic matter content was measured via the external heating potassium dichromate volumetric method; available $\mathrm{N}$ was determined using the diffusion method; available $\mathrm{P}$ was extracted with $\mathrm{HCl}-\mathrm{NH}_{4} \mathrm{~F}$ and measured via the molybdate blue method; available $\mathrm{K}$ was determined via flame photometry after extraction with $1.0 \mathrm{M} \mathrm{NH}_{4} \mathrm{OAC}$; and $\mathrm{Ca}$ and $\mathrm{Mg}$ were measured using inductively coupled plasma optical emission spectrometry (Varian 710 ES; Agilent, Santa Clara, CA). Leaf N, P, and K were measured using the diffusion method, molybdate blue method, and flame photometry method, respectively, after dissolution in $\mathrm{H}_{2} \mathrm{SO}_{4}-\mathrm{H}_{2} \mathrm{O}_{2}$ (Bao, 2000). The leaf $\mathrm{Ca}$ and $\mathrm{Mg}$ were dissolved in $0.5 \mathrm{M} \mathrm{HNO}_{3}$ and measured using inductively coupled plasma optical emission spectrometry (Zhou et al., 2014).

The data were analyzed with RStudio 3.5 software for Windows (The R Project for

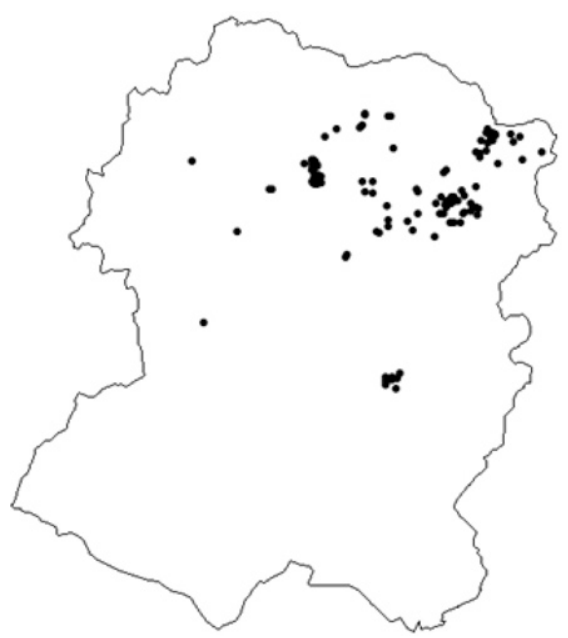

Fig. 1. The distribution of sampling points of farmers $(n=75)$. The solid boundary line represents the location of Luniao County. The black dot represents the sampling location.
Table 2. Pear yield and the yield-limiting factors.

\begin{tabular}{|c|c|c|c|}
\hline Category & Factors & Mean & Range \\
\hline \multirow[t]{3}{*}{ Yield } & Yield $\left(\mathrm{t} \cdot \mathrm{ha}^{-1} \cdot \mathrm{year}^{-1}\right)$ & $16.50 \pm 5.21$ & $3.6-27$ \\
\hline & Organic matter $\left(\mathrm{g} \cdot \mathrm{kg}^{-1}\right)$ & $29.9 \pm 9.96$ & $8.4-71.6$ \\
\hline & Available N (mg·kg $\left.{ }^{-1}\right)$ & $136.4 \pm 42.36$ & $73.5-389.2$ \\
\hline \multirow{6}{*}{ Soil factors } & Available $\mathrm{P}\left(\mathrm{mg} \cdot \mathrm{kg}^{-1}\right)$ & $244.1 \pm 136.82$ & $23.2-583.8$ \\
\hline & Available $\mathrm{K}\left(\mathrm{mg} \cdot \mathrm{kg}^{-1}\right)$ & $296.7 \pm 145.98$ & $69.5-984.0$ \\
\hline & Soluble $\mathrm{Ca}\left(\mathrm{mg} \cdot \mathrm{kg}^{-1}\right)$ & $611.7 \pm 371.5$ & $84.9-2357.5$ \\
\hline & Soluble $\mathrm{Mg}\left(\mathrm{mg} \cdot \mathrm{kg}^{-1}\right)$ & $94.7 \pm 127.5$ & $14.8-934.1$ \\
\hline & Fertilizer $\mathrm{N}$ application $\left(\mathrm{kg} \cdot \mathrm{ha}^{-1}\right)$ & $980 \pm 626.9$ & $215.3-3390.2$ \\
\hline & Fertilizer $\mathrm{P}_{2} \mathrm{O}_{5}$ application $\left(\mathrm{kg} \cdot \mathrm{ha}^{-1}\right)$ & $848 \pm 1043.4$ & 141.12-9084.3 \\
\hline \multirow[t]{6}{*}{ Agronomy factors } & Fertilizer $\mathrm{K}_{2} \mathrm{O}$ application $\left(\mathrm{kg} \cdot \mathrm{ha}^{-1}\right)$ & $825 \pm 560.0$ & $113.4-2643.2$ \\
\hline & Organic fertilizer ratio (\%) & $45.1 \pm 22.2$ & $0-86.8$ \\
\hline & Pest and disease control (no.) & $6.8 \pm 2.5$ & $0-11.0$ \\
\hline & Density (plants/ha) & $1089.0 \pm 340.1$ & $495.0-1665.0$ \\
\hline & Tree age (year) & $16.9 \pm 5.5$ & $5.0-32.0$ \\
\hline & Leaf N (\%) & $1.6 \pm 0.3$ & $07-2.5$ \\
\hline \multirow{4}{*}{ Internal factors } & Leaf P (\%) & $0.2 \pm 0.4$ & $0-0.3$ \\
\hline & Leaf K (\%) & $1.6 \pm 0.3$ & $1.2-2.7$ \\
\hline & Leaf $\mathrm{Ca}(\%)$ & $1.8 \pm 0.4$ & $0.9-2.8$ \\
\hline & Leaf $\mathrm{Mg}(\%)$ & $0.3 \pm 0.1$ & 0.10 .5 \\
\hline
\end{tabular}

Data is average \pm SD.

$\mathrm{Ca}=$ calcium $\mathrm{K}=$ potassium $; \mathrm{Mg}=$ magnesium; $\mathrm{N}=$ nitrogen $\mathrm{P}=$ phosphorus.
Statistical Computing, Vienna, Austria). Yield-limiting factors and the contribution rate of different indices were analyzed using the boundary lines model with Microsoft were drawn using Sigmaplot 12.5 (Systat Software, Bengaluru, India).

Data analysis methods. The approach to building boundary lines during this study was based on the methods described by Chen et al. (2018) and included the following main steps: 1) establishing scatter plots of pear yield and yield-related limiting factors; 2) identifying upper boundary points for every limiting factor; and 3) fitting a curve using the upper boundary points.

The total gap was considered the difference between the highest attainable yield and Office 2016 (Redmond, WA), and figures farmers' actual yield; this includes the explainable gap, which is caused by individual limiting factors, and the unexplainable gap, which is caused by other unknown factors (Cao et al., 2019). The explainable gap represented the total gap in this study. Moreover, according to von Liebig's law of the minimum (von Liebig, 1840), the most significant limiting factor was used to explain the yield gap. The average contribution proportion of different factors was calculated assuming that the total percentage of all factors was $100 \%$.

A scenario analysis was used to predict the best yield-increasing strategy. Current yield improvement strategies based on fertilization include soil testing and fertilization technology, as well as leaf nutrition diagnosis. Crop yield is affected by various factors, such

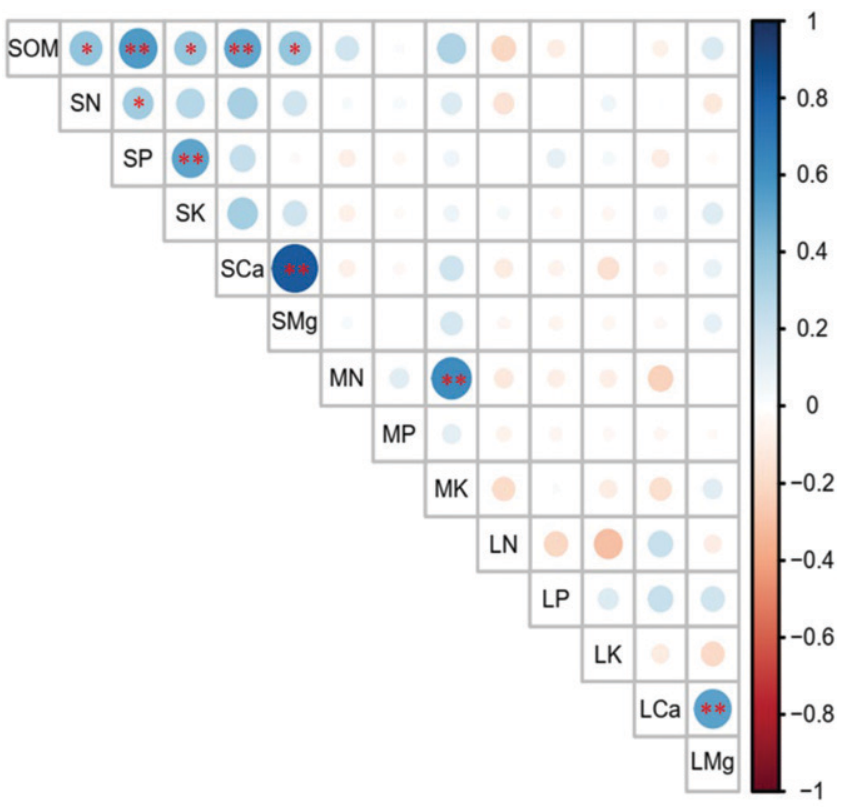

Fig. 2. The correlation analysis of different production restriction factors $(n=75)$. The contents of soil organic matter (SOM), soil-available nitrogen (SN), soil-available phosphorus (SP), soil-available potassium (SK), soluble calcium ( $\mathrm{SCa}$ ), and soluble magnesium $(\mathrm{SMg})$ are shown. $\mathrm{MN}, \mathrm{MP}$, and MK represent the application rates of $\mathrm{N}, \mathrm{P}_{2} \mathrm{O}_{5}$, and $\mathrm{K}_{2} \mathrm{O}$, respectively. $\mathrm{LN}, \mathrm{LP}, \mathrm{LK}, \mathrm{LCa}$, and $\mathrm{LMg}$ represent the nutrient contents of leaf $\mathrm{N}, \mathrm{P}, \mathrm{K}, \mathrm{Ca}$, and $\mathrm{Mg}$, respectively. 
as soil factors, management factors, and leaf factors. Therefore, we assumed that a comprehensive improvement strategy that considers multiple factors would be the best strategy for improving production. Accordingly, we set three scenarios: $\mathrm{S}_{\mathrm{i}}$ (soil test and fertilization technology); $\mathrm{S}_{\mathrm{ii}}$ (leaf nutrient diagnosis technology); and $\mathrm{S}_{\mathrm{iii}}$ (comprehensive management technology). For $\mathrm{S}_{\mathrm{i}}$, the best fertilizer application rate was calculated using the pear nutrient absorption regulation and soil nutrient content. We calculated the increasing yield by summing the current yield with the farmers' previous yield for which the fertilizer rate and soil content were within reasonable ranges.
A

Soil

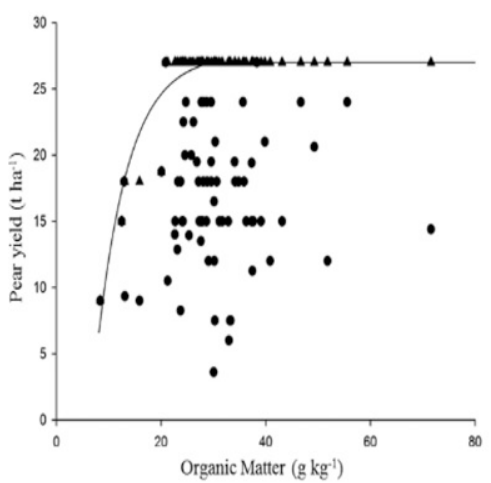

factors
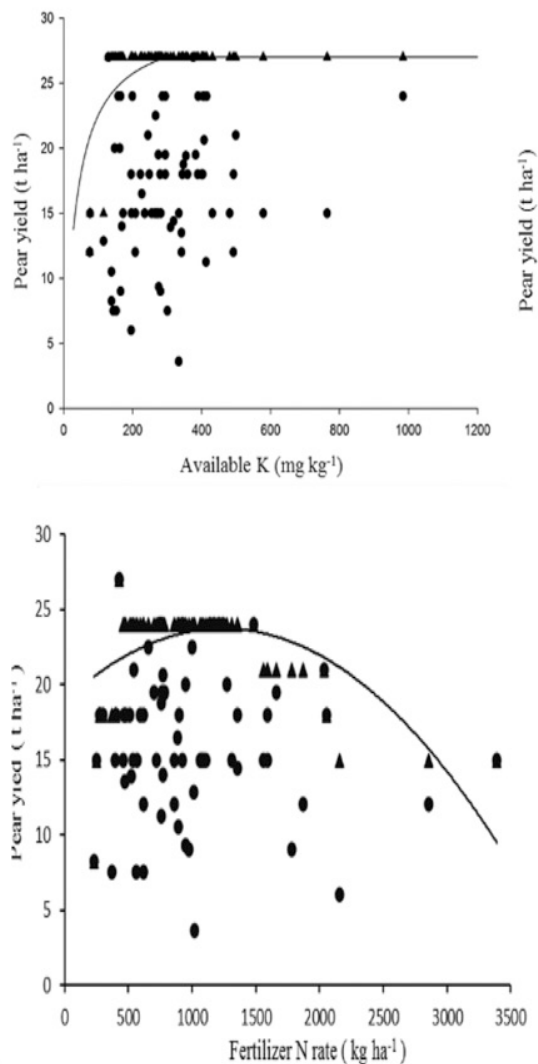

Agronomy factors

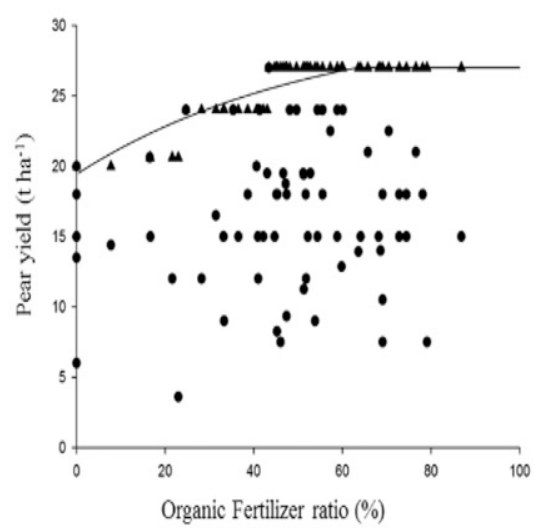

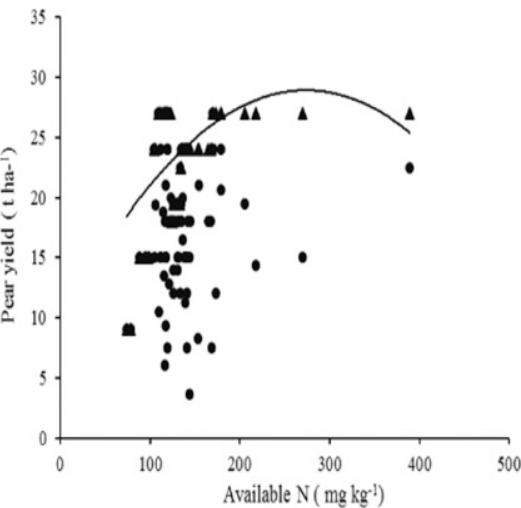
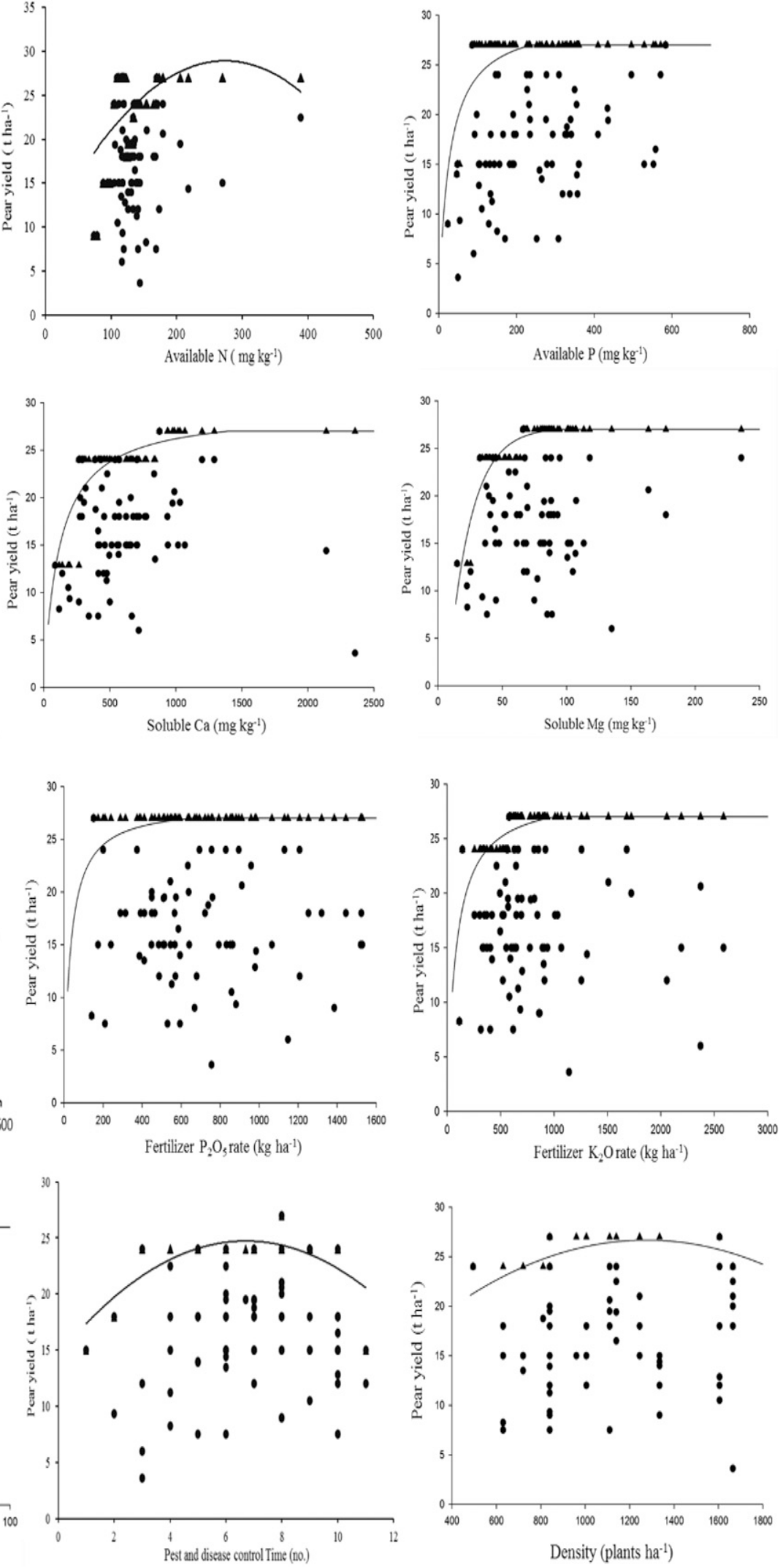

Fig. 3. (Continued.) 

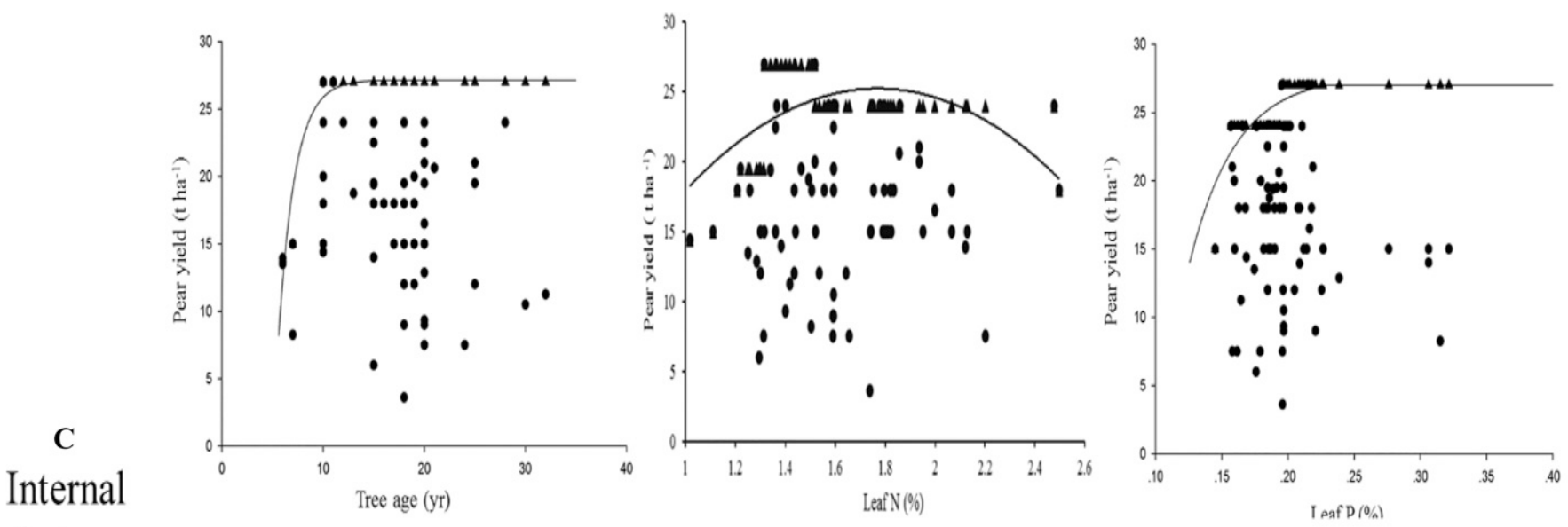
factors
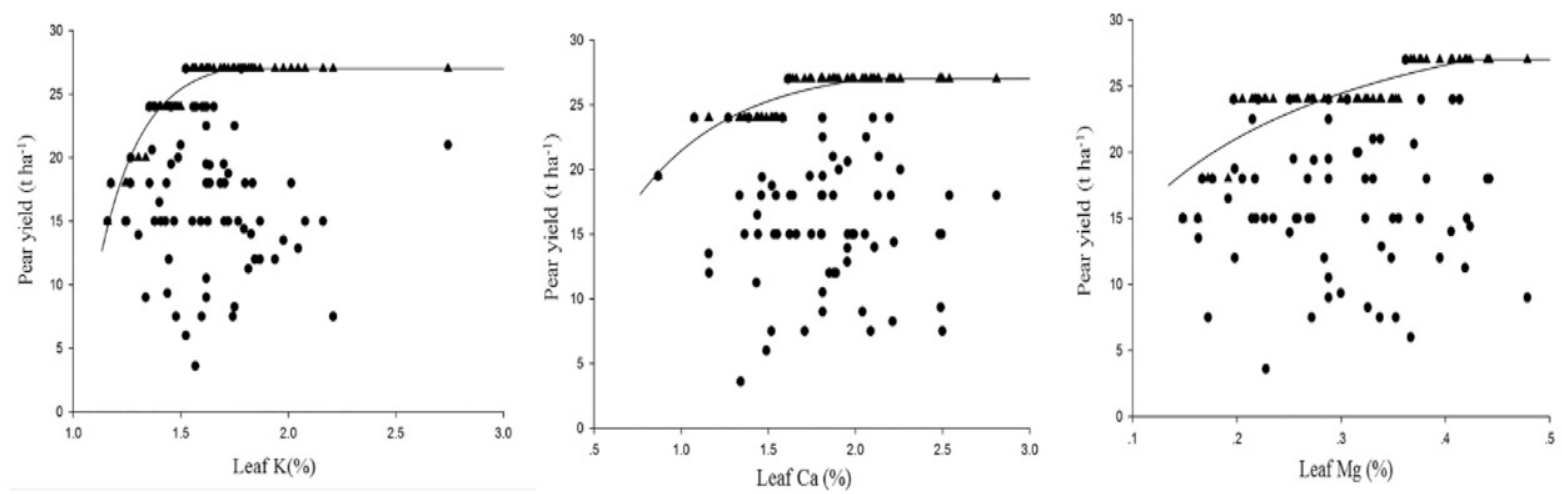

Fig. 3. The relationship between pear yield and soil factors $(\mathbf{A})$, agronomy practice factors $(\mathbf{B})$, and internal factors $(\mathbf{C})$. The soil factors include soil organic matter, available nitrogen $(\mathrm{N})$, available phosphorus $(\mathrm{P})$, available potassium $(\mathrm{K})$, soluble calcium $(\mathrm{Ca})$, and magnesium $(\mathrm{Mg})$. The agronomy factors include mineral fertilizer $\mathrm{N}$ inputs, mineral fertilizer $\mathrm{P}_{2} \mathrm{O}_{5}$ inputs, mineral fertilizer $\mathrm{K}_{2} \mathrm{O}$ input, the ratio of manure fertilizer, density, and the frequency of controlling pests and disease. The internal factors include tree age, leaf $\mathrm{N}$ content, leaf $\mathrm{P}$ content, leaf $\mathrm{K}$ content, leaf $\mathrm{Ca}$ content, and leaf Mg content. The black dots represent the yield that farmers can obtain. The black triangle represents the boundary point. The solid black line represents the boundary line.

For $\mathrm{S}_{\mathrm{ii}}$, we hypothesized that the increasing fertilizer ratio was the sum of every leaf nutrient content ratio from the current average value to the optimum value. Increasing the yield ratio followed the same rule as $\mathrm{S}_{\mathrm{i}}$, for which the leaf contents were within reasonable intervals. For $\mathrm{S}_{\mathrm{iii}}$, we selected two main limiting factors of soil, management, and internal factors according to the boundary line model; the increasing fertilizer and yield ratio was the sum of the limiting factors according to the reasonable range and current average value.

\section{Results}

Pear yield gap and basic management. The average yield of pear was $16.5 \mathrm{t} \cdot \mathrm{ha}^{-1}$. year $^{-1}$, and the yield gap was $10.5 \mathrm{t} \cdot \mathrm{ha}^{-1}$. year $^{-1}$ (Table 1). This translated to an income gap of $\$ 19,384.60$ per ha $^{-1}$. year ${ }^{-1}$.

The basic results of soil factor analysis (soil organic matter, available $\mathrm{N}$, available $\mathrm{P}$, available $\mathrm{K}$, soluble $\mathrm{Ca}$, and soluble $\mathrm{Mg}$ ), agronomy factor analysis (mineral fertilizer $\mathrm{N}$ inputs; mineral fertilizer $\mathrm{P}_{2} \mathrm{O}_{5}$ inputs; mineral fertilizer $\mathrm{K}_{2} \mathrm{O}$ inputs; and the ratio of manure fertilizer, density, and pest and disease time), and internal factor analysis (tree age, leaf $\mathrm{N}$ content, leaf $\mathrm{P}$ content, leaf $\mathrm{K}$ content, leaf $\mathrm{Ca}$ content, and leaf $\mathrm{Mg}$ content) are shown in Table 2.

Positive correlations were found between soil $\mathrm{N}$ and $\mathrm{P}, \mathrm{P}$ and $\mathrm{K}$, and $\mathrm{Ca}$ and $\mathrm{Mg}$; between the input rates of $\mathrm{P}_{2} \mathrm{O}_{5}$ and $\mathrm{K}_{2} \mathrm{O}$; and between leaf $\mathrm{Ca}$ and $\mathrm{Mg}$ (Fig. 2). Overall, the fertilizer application rate used as management practice was not significantly correlated with the soil nutrient content, although it showed a positive correlation trend (Fig. 2). The correlation between the soil nutrient content and leaf mineral element content was weak (Fig. 2).

Yield-limiting factors and their contributions to the yield gap. The relationships between the pear yield and 18 yield constraint factors were evaluated using the boundary line model (Fig. 3A-C).

Overall, the chemical $\mathrm{N}$ fertilizer input rate was the most common yield constraint (accounting for 16.4\%), followed by the soilavailable $\mathrm{N}$ content $(15.5 \%)$ and pest and disease control time (13.0\%) (Fig. 4). The leaf Mg content (12.0\%) was the most important leaf factor. The two least significant yieldlimiting factors were the $\mathrm{P}_{2} \mathrm{O}_{5}$ input rate $(1.6 \%)$ and tree age $(2.8 \%)$.

From the perspective of factors at the farmer level (Fig. 5), soil factors were the most significant index affecting pear yield, accounting for $40.0 \%$. The management $\mathrm{N}$ input rate was the dominant individual factor $(16.0 \%)$, which was also the most important factor according to the farmers themselves. Internal factors also significantly affected yield, accounting for $25.3 \%$, with leaf $\mathrm{Mg}$ content $(10.7 \%)$ being the most important yield constraint among them.
Scenario analysis. Based on the defined yield-limiting factors, we set three different scenarios for increasing yield (Table 3). For $\mathrm{S}_{\mathrm{i}}$, soil testing and fertilization technology were applied. Using this strategy, the yield was projected to increase by $6 \%$ and the fertilizer use rate decreased by $78 \%$ because the fertilizer input rates were required to decrease by nearly $2100 \mathrm{~kg} \cdot \mathrm{ha}^{-1}\left(\mathrm{~N}+\mathrm{P}_{2} \mathrm{O}_{5}+\mathrm{K}_{2} \mathrm{O}\right)$. For $\mathrm{S}_{\mathrm{ii}}$, the leaf diagnosis was applied; the application of fertilizer increased by $27 \%$ because the average nutrient value was lower than the normal value, and the yield increased by $5 \%$. For $\mathrm{S}_{\mathrm{iii}}$, after comprehensively optimizing the soil nutrients, management practices, and internal factors combined with boundary lines, fertilizer use rates decreased by $66 \%$ and the yield increased by $14 \%$, which was the largest increase compared with the other scenarios.

\section{Discussion}

Pear yield gap for smallholders in China. Based on our survey results, the yield of pears in this area ranges from 3.6 to $27 \mathrm{t} \cdot \mathrm{ha}^{-1}$. year ${ }^{-1}$, revealing variations in yield between smallholders. These gaps may be related to differences in cultivation techniques attributable to the gender, age, and education level of the farmers (Zhang et al., 2019a). In addition, the local average pear yield is $16.5 \mathrm{t} \cdot \mathrm{ha}^{-1}$. year $^{-1}$, which is lower than the average of 


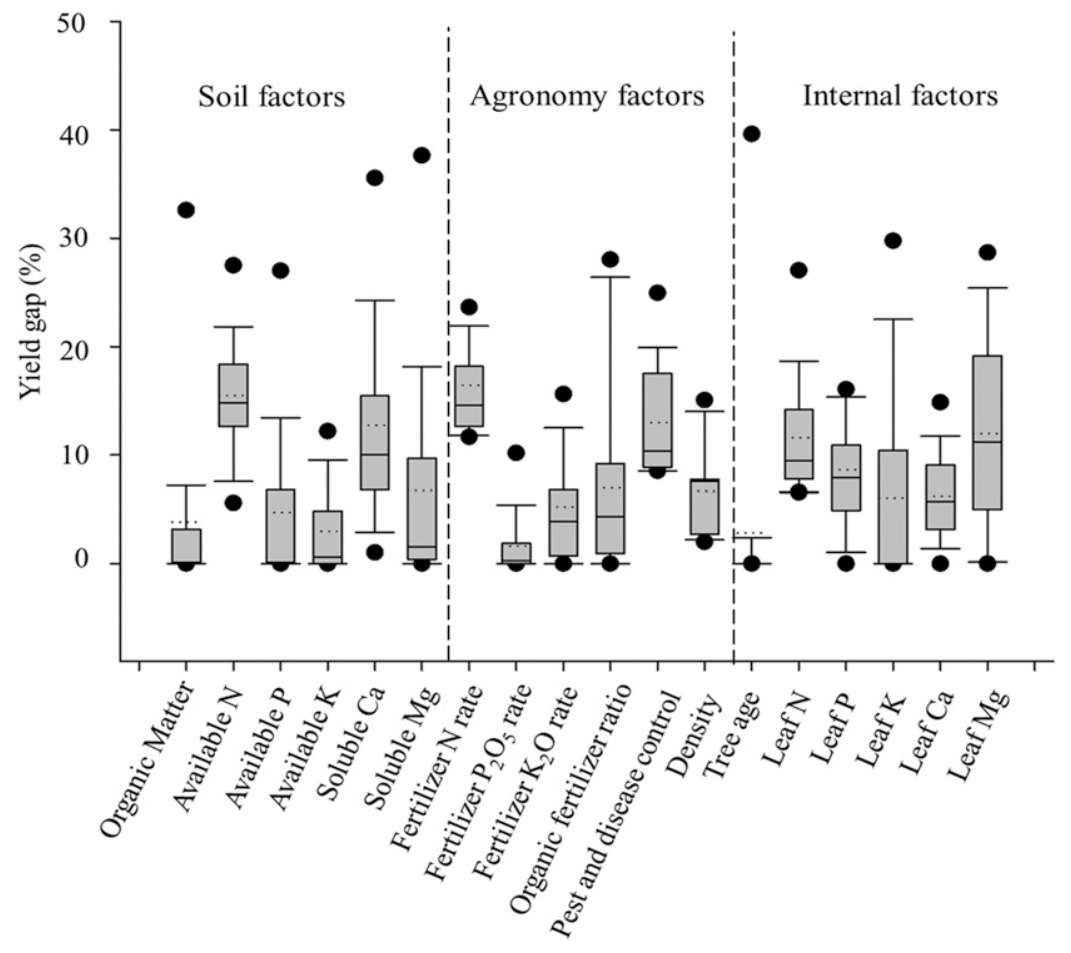

Fig. 4. The yield gap of different yield-limiting factors at the regional level $(n=75)$. The box boundaries indicate the upper and lower quartiles. The whisker caps indicate the 95th and 5th percentiles. The dotted line represents the average. $\mathrm{Ca}=$ calcium; $\mathrm{K}=$ potassium; $\mathrm{Mg}=$ magnesium; $\mathrm{N}=$ nitrogen; $\mathrm{P}=$ phosphorus.

high-yield countries such as the United States and Switzerland (FAO, 2019). This difference may be because of a shortage of labor, lack of knowledge (Tittonell et al., 2013; Vandeplas et al., 2010), or smaller planting area per capita (Wang et al., 2016), resulting in a lack of scientific management and standardized production capacity. Therefore, changing the

overall industry model and improving farmer management techniques are important.

Yield-related individual limiting factors of pear. Smallholders have the most important role in crop production in China (Cao et al., 2019). Under specific hydrological and climatic conditions, unsuitable management and soil conditions have a notable impact on yield

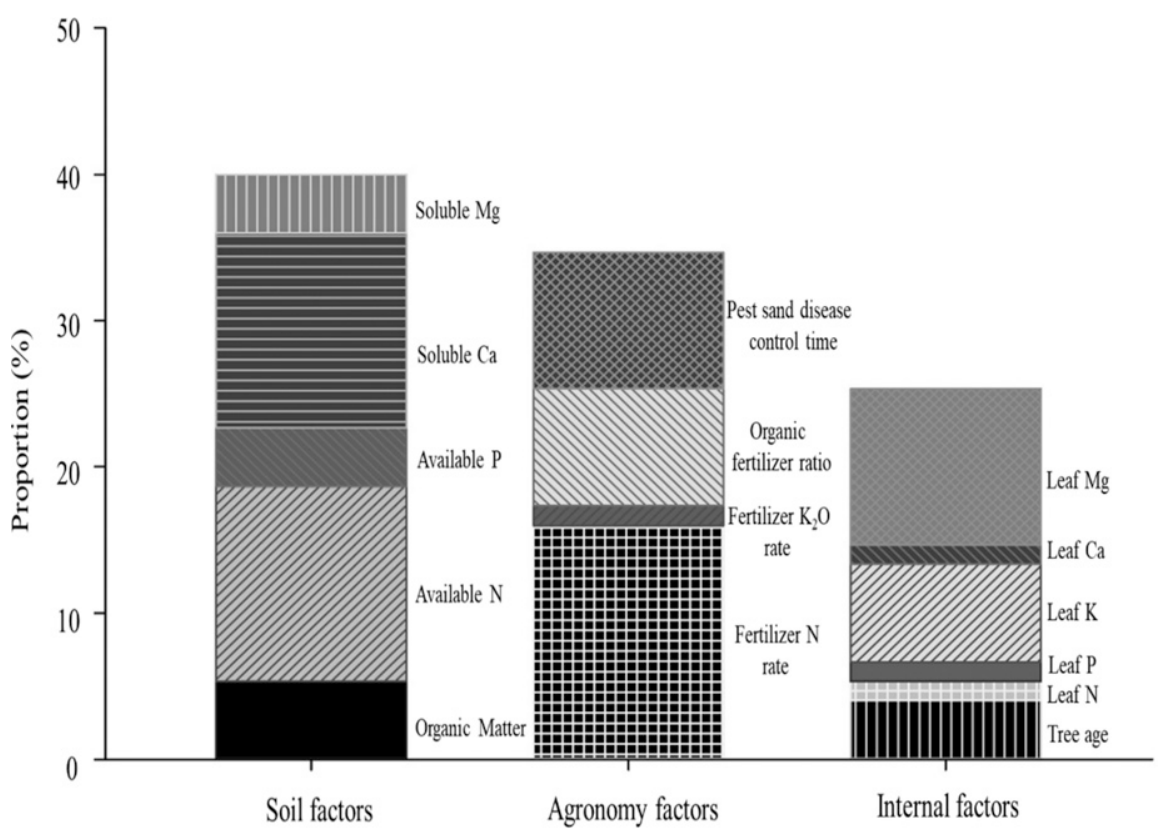

Fig. 5. The proportion of dominant factors that influence the pear yield at the farmer level $(n=75)$. The proportion of each factor indicates the percentage of the number of farmers. Tis factor is highest than any other factors divided by the total number of interviewed farmers. $\mathrm{Ca}=$ calcium; $\mathrm{K}=$ potassium; $\mathrm{Mg}=$ magnesium; $\mathrm{N}=$ nitrogen; $\mathrm{P}=$ phosphorus.
(Grassini et al., 2011). Many studies reported that fertilizer application rates of most farmers of cash crops are higher than the recommended value in China, particularly for $\mathrm{N}$ fertilizer (Weinbaum et al., 1992; Zhang et al., 2018), which greatly constrains the vegetative growth of trees and the yield (Ma et al., 2020; Ndabamenye et al., 2013). A study of apples by Zhang et al. (2018) indicated that the amount of basal fertilizer $\mathrm{N}$ of smallholders was among the top three yield-limiting factors in China, which is similar to the results of our study. Large-scale application of $\mathrm{N}$ fertilizer occurs because of the farmers' lack of scientific fertilization knowledge (Lobell et al., 2009). Many farmers are not familiar with the nutrient marks on fertilizer bags, such as "20-16-9," and they cannot calculate the nutrient demand of crops (Zhang et al., 2016). Moreover, most farmers fertilize the field surface rather than using deep fertilization techniques because they have limited time to devote to agricultural activities ( $\mathrm{Lu}$ et al., 2008; Vandeplas et al., 2010). Our research found that the optimal amount of $\mathrm{N}$ fertilizer calculated by the boundary line was higher than the recommended amount because the nutrient use efficiency was lower. Therefore, translating scientific knowledge into farming action, such as using the Science and Technology Backyard mode (Zhang et al., 2016), while developing innovation technologies to reduce labor time should greatly improve yield.

Soil is a mineral reserve that stores various nutrients necessary for normal growth; therefore, soil fertility parameters are closely correlated with one another (Rahman et al., 2011). This is similar to our findings that soil organic matter, soil $\mathrm{N}$, soil $\mathrm{P}$, soil $\mathrm{K}$, soil $\mathrm{Ca}$, and soil $\mathrm{Mg}$ are strongly correlated with each other. Additionally, in our study, the leaf $\mathrm{Ca}$ and $\mathrm{Mg}$ contents were positively correlated (Fig. 2), which is consistent with the finding of Song et al. (2011). However, Wang et al. (2019) found that the leaf $\mathrm{N}$ content was negatively correlated with the leaf $\mathrm{Ca}$ and $\mathrm{Mg}$ contents but positively correlated with the leaf $\mathrm{K}$ content, which was in contrast to our results. This may be because the crop variety and research sites were different. Overall, different limiting factors are not isolated, but they are closely related. Therefore, to formulate strategies to optimize yield, changes in yield caused by synergy and antagonism between elements should be further investigated.

Overall yield-limiting factors of pears. From the perspective of soil, agronomy practice, and internal factors, our results showed that soil factors have the most significant effect on the yield of pear orchards, which is in agreement with the results of Sussy et al. (2020). It is likely that soil is a direct source of nutrients for trees and directly affects the growth and development of crops (Song, 2017). In addition, internal factors, such as the elemental content of leaves, are closely related to fruit crop yield. This may be because proteins and fats, among other macromolecules, are synthesized in the leaves (Dar et al., 2015). Therefore, the effects of internal factors on pear yield are important, and appropriate 
Table 3. Scenario analysis of different management methods use for fertilizer application and yield.

Increasing rate $(\%)$

Total

fertilizer

\begin{tabular}{ccccc} 
& Category & Contents & $\begin{array}{c}\text { rate } \\
\text { rate }\end{array}$ & Yield \\
\hline $\mathrm{S}_{\mathrm{i}}$ & $\begin{array}{c}\text { Soil testing and } \\
\text { fertilization }\end{array}$ & $\begin{array}{c}\text { Optimized soil (available N, P, and K) management } \\
\text { (fertilizer N, P, and K inputs) }\end{array}$ & $-78 \%$ & $+6 \%$ \\
$\mathrm{~S}_{\mathrm{ii}}$ & Leaf diagnosis & Optimized leaf nutrients (leaf N, P, K, Ca, and Mg) & $+27 \%$ & $+5 \%$ \\
$\mathrm{~S}_{\mathrm{iii}}$ & $\begin{array}{c}\text { Comprehensive } \\
\text { optimization }\end{array}$ & $\begin{array}{c}\text { Optimized soil (soluble Ca and available N) management } \\
\text { (fertilizer N inputs and pest and disease control time) }\end{array}$ & $-66 \%$ & $+14 \%$ \\
& & \begin{tabular}{l} 
and internal factors (leaf N and leaf Mg) \\
\hline
\end{tabular} & & \\
\hline
\end{tabular}

The fertilizer and yield increasing rate were calculated according to all farmers average value and the part of farmers whose management methods are at the reasonable range level.

$\mathrm{Ca}=$ calcium; $\mathrm{K}=$ potassium; $\mathrm{Mg}$ = magnesium; $\mathrm{N}=$ nitrogen; $\mathrm{P}=$ phosphorus.

measures should be taken to ensure an appropriate nutrient content in the leaves.

In terms of soil nutrient concentration and leaf mineral element content, we found a weak correlation between soil and leaf variables (Fig. 1). Khattak and Hussain (2007) concluded that the relationship between orchard soil nutrients and tree nutrient levels is very complicated. When the soil nutrient content was high, the corresponding nutrient content of fruit trees was not always high (Khattak and Hussain, 2007). However, Wang et al. (2019) suggested that there is a definite correlation between the soil nutrient content and leaves. Further research is necessary to determine the correlation between soil and leaves and to formulate more reasonable fertilization management strategies.

Method and strategy for yield improvement. Soil analysis can reveal the availability of soil nutrients; furthermore, soil testing and fertilization technology can be used to develop a fertilization strategy, which is helpful for reducing the impact of unbalanced fertilization and increasing efficiency (Hu and Zhou, 2011). Additionally, pear is a perennial crop in which nutrients are stored in the trunk (Cheng and Raba, 2009); therefore, diagnosis technology for trees, such as leaf nutrient diagnosis technology (Diagnosis and Recommendation Integrated System), is widely used to determine the status of tree nutrient deficiency (Beaufils, 1973). Combining these methods may be an effective strategy for improving fruit yield (Du, 1977).

The boundary line model is a comprehensive method that can identify key limiting factors and combine the various factors of soil, management, and leaf nutrients, which is helpful for developing strategies to increase yield. According to our results, if optimized strategies are applied to all Chinese pear orchards (1.0 million ha), then fertilizer use can be decreased by 1.3 million tons while increasing yield by 2.0 million tons. Our research revealed the contribution of internal factors to yield but did not consider the interactions among factors. Therefore, the development of soil-, leaf-, and managementbased models that consider the interaction of different factors may help to achieve even higher crop yields.

\section{Conclusion}

We found that smallholder farmers have large yield gaps between the actual yield and high yield of Chinese pear. Soil, agronomy, and internal factors are important yield-limiting factors. From the individual factor perspective, the amount of $\mathrm{N}$ fertilizer input (agronomy factor) is the most critical factor limiting yield, followed by the soil-available $\mathrm{N}$ content (a soil factor) and leaf $\mathrm{Mg}$ content (an internal factor). Overall, soil factors were the dominant yieldlimiting factor group. Additionally, the impact of internal factors was significant. Research based on a scenario analysis showed that comprehensive management methods that consider soil, agronomy, and internal factors will greatly increase yields. Our findings indicate that further studies aimed at pear yield improvement should consider internal factors, and that comprehensive management measures are vital for further development of the pear industry. Furthermore, the influence of synergy and antagonism between different factors on the yield should be determined to achieve further improvement.

\section{Literature Cited}

Aruani, M.C., P.D. Reeb, and N.E. Barnes. 2014. Influence of soil properties on yield and fruit maturity at harvest of 'Williams' pear. Chil. J. Agr. Res. 74(4):460-467, https://doi.org/10.4067/ S0718-58392014000400013.

Awasthi, R.P., V.P. Bhutani, J.C. Sharma, and N.S. Kaith. 1998. Mineral nutrient status of apple orchards of Shimla district of Himachal Prasesh. Indian J. Hort. 55:314-322.

Babu, K. and D. Yadav. 2005. Foliar spray of micro-nutrients for yield and quality improvement in Khasi mandarin (Citrus reticulate Blano.). Indian J. Hort. 62:280-281, https://doi. org/10.31830/2348-7542.2019.047.

Bao, S.D. 2000. Soil analysis in agricultural chemistry. Chinese Agriculture Publishing House, Beijing, China

Beaufils, E. 1973. Diagnosis and recommendation integrated system (DRIS). A general scheme for experimentation and calibration based on principles developed from research in plant nutrition, Soil Science Bulletin 1: University of Natal, Department of Soil Science and Agrometeorology, Pietermaritzburg, South Africa. 132.

Bist, L. and A. Yadav. 2004. Long term studies on planting system-cum-density of planting in low-chill soft pear under subtropical conditions.
Acta Horticulturae 662(1):217-220, https://doi. org/10.17660/ActaHortic.2004.662.30.

Cao, H.Z., Y.N. Li, G.F. Chen, D.D. Chen, H.R. Qu, and W.Q. Ma. 2019. Identifying the limiting factors driving the winter wheat yield gap on smallholder farms by agronomic diagnosis in North China Plain. J. Integr. Agr. 18(8):1701-1713, https://doi.org/10.1016/S2095-3119(19)62574-8.

Chen, G.F., H.Z. Cao, J. Liang, W.Q. Ma, L.F. Guo, S.H. Zhang, R.F. Jiang, H.Y. Zhang, K.W. Goulding, and F.S. Zhang. 2018. Factors affecting nitrogen use efficiency and grain yield of summer maize on smallholder farms in the north China plain. Sustainability 10:363, https://doi.org/10.3390/su10020363.

Cheng, L.L. and R. Raba. 2009. Accumulation of macro- and micronutrients and nitrogen demandsupply relationship of 'Gala'/'Malling 26' apple trees grown in sand culture. J. Amer. Soc. Hort. Sci. 134(1):3-13, https://doi.org/10.21273/jashs. 134.1.3.

Dar, M., J.A. Wani, S.K. Raina, M.Y. Bhat, and M.A. Malik. 2015. Relationship of leaf nutrient content with fruit yield and quality of pear. $\mathrm{J}$. Environ. Biol. 36(3):649-653.

De Melo-Abreu, J.P., M. Sousa, and J. Lopes. 2015. CSS-Pear: A model to simulate growth, production and quality of pear (Pyrus communis L.). Acta Horticulturae 1094:223-231, https://doi. org/10.17660/actahortic.2015.1094.28.

Du, P. 1977. Soil analysis as a necessary complement to leaf analysis for fertilizer advisory purposes. Proceedings of the International Society of Citriculture 1:15-20.

Duarte, L., P.V. Jordão, F. Calouro, and R. Sousa. 2010. Management of nitrogen and potassium fertilizer inputs on fertigated pear orchards and its influence on yield and fruit quality. Acta Hort. 868:307-311, https://doi.org/10.17660/ actahortic.2010.868.40.

FAO (Food and Agriculture Organization of the United Nations). 2019. FAOSTAT. DatabaseResources. Food and Agriculture Organization of the United Nations. <http://www.fao.org/ faostat/zh/\#home $>$.

Feng, Y., J. Wei, G.F. Zhang, X.Y. Sun, W. Wang, C.Y. Wu, M. Tang, Z.Y. Gan, X.Z. Xu, and S.M. Chen. 2018. Effects of cooling measures on 'Nijisseiki' pear (Pyrus pyrifolia) tree growth and fruit quality in the hot climate. Scientia Hort. 238:318-324, https://doi.org/10.1016/j. scienta.2018.05.002.

Glenn, D.M., G. Puterka, T. Zwet, and R. Byers. 1997. Hydrophobic particles for pest control in deciduous tree fruit production. HortScience 32:467, https://doi.org/10.21273/hortsci.32.3. $467 \mathrm{~d}$.

Gomand, A., J. Vercammen, V. Siongers, and D. Bylemans. 2018. Multiyear field trials to balance the nutrition of nitrogen and potassium for 'Conference' pear. Acta Hort. 1217:239-245, https://doi.org/10.17660/actahortic.2018.1217.30.

Grassini, P., J. Thorburn, C. Burr, and K.G. Cassman. 2011. High-yield irrigated maize in the Western U.S. Corn Belt: I. On-farm yield, yield potential, and impact of agronomic practices. Field Crops Res. 120:142-150, https://doi.org/ 10.1016/j.fcr.2010.09.012.

Hu, Z. and J. Zhou. 2011. Discussion on fertilizer development and scientific application. Chinese Agr. Resources 8(8):53-54 (in Chinese).

Khattak, R. and Z. Hussain. 2007. Evaluation of soil fertility status and nutrition of orchards. Soil Environ. 26(1):22-32.

Kumar, T.S., J. Kumar, and M. Kumar. 2007 Effect of leaf nutrient status on yield and quality of kiwi fruit (Actinidia deliciosa Chev.) Indian J. Hort. 64:77-78. 
Li, H., J. Zhao, A. Ren, M. Sun, W. Lin, and Z.Q. Gao. 2020. Closing the yield gap and achieving high water use efficiency with field management practices in dryland wheat: a case study on the loess plateau. Intl. J. Agr. Biol. 24(6):15431550, https://doi.org/10.17957/IJAB/15.1593.

Li, T. 2014. Research on the integration degree of my country's pear fruit market-taking Ya pear as an example. Agricultural Development and Equipment 4:16-18 (in Chinese).

Liu, X., L. Chen, B. Wang, Y. Fan, and Q. Chen. 2016. 29th International Horticultural Congress on Horticulture - Sustaining Lives, Livelihoods and Landscapes (IHC). Brisbane, Australia, 17-22 Aug. 2014.

Liu, X., Q. Chen, B. Wang, B. Zhang, J. Li, and L. Chen. 2013. Influences of different ratios of nitrogen supplied from manure and mineral fertilizers on 'nanguo' pear growth and soil nutrient accumulation. Acta Hort. 984:257-262, https://doi.org/10.17660/actahortic.2013.984.29.

Lobell, D.B., K.G. Cassman, and C.B. Field. 2009. Crop yield gaps: Their importance, magnitudes, and causes. Annu. Rev. Environ. Resour. 34:179-204, https://doi.org/10.1146/annurev. environ.041008.093740.

Lu, S.C., Q. Chen, F.S. Zhang, and W.Z. Jia. 2008. Characteristics of nitrogen input in orchards and analysis of soil nitrogen load in Hebei Province. J. Plant Nutrition and Fert. 14(5):858-865. (in Chinese).

Ma, Q.X., Y. Wen, D.Y. Wang, X.D. Sun, P.W. Hill, A. Macdonald, D.R. Chadwick, L.H. Wu, and D.L. Jones. 2020. Farmyard manure applications stimulate soil carbon and nitrogen cycling by boosting microbial biomass rather than changing its community composition. Soil Biol. Biochem. 144:1-11, https://doi.org/ 10.1016/j.soilbio.2020.107760

Mahbubeh, Y., S. Afshin, D. Salman, and A. Hossein. 2021. Yield gap assessment in rice-grown fields using CPA and BLA approaches in northern Iran. Intl. J. Plant Prod. 15(2):203-217, https://doi.org/10.1007/s42106-020-00128-y.

Maria, C.A., D.R. Pablo, and E.B. Norma. 2014. Influence of soil properties on yield and fruit maturity at harvest of 'Williams' pear. Chilean J. Agr. Res. 74(4):460-467, https://doi.org/10.4067/ S0718-58392014000400013.

Ndabamenye, T., P.J.A.V. Asten, G. Blomme, B. Vanlauwe, B. Uzayisenga, J.G. Annandale, R.O. Barnard. 2013. Nutrient imbalance and yield limiting factors of low input East African highland banana (Musa spp. AAA-EA) cropping systems. Field Crops Res. 147:68-78, https:// doi.org/6878.10.1016/j.fcr.2013.04.001.

Rahman, M.H., A.W. Holmes, A.G. McCurran, and S.J. Saunders. 2011. Impact of management systems on soil properties and their relationships to kiwifruit quality. Commun. Soil Sci. Plant Anal. 42:332-357, https://doi.org/ 10.1080/00103624.2011.538884.

Song, R. 2017. Analysis of soil nutrients and tree nutrient abundance and deficiency status of main pear orchards in the Yellow River Basin. Nanjing Agricultural University, Nanjing, China (in Chinese).

Song, X.H., K. Xie, H.B. Zhao, Y.L. Li, Y.C. Xu, and C.X. Dong. 2011. Study on the mineral nutrient element status of main pear orchards in the Bohai Bay area. Acta Hort. 38(11):2049-2058 (in Chinese).

Song, Y., L. Fan, H. Chen, M.Y. Zhang, Q.Q. Ma, S.L. Zhang, and J. Wu. 2014. Identifying genetic diversity and a preliminary core collection of Pyrus pyrifolia, cultivars by a genome-wide set of SSR markers. Scientia Hort. 167:5-16, https:// doi.org/10.1016/j.scienta.2013.12.005.

Sussy, M., A.S. Dahlin, M.C. Onyango, K.W Oluoch, and H. Marstrop. 2020. Soil and management-related factors contributing to maize yield gaps in western Kenya. Food Energy Secur. 9(1):1-17, https://doi.org/10.1002/fes3.189.

Tittonell, P. and K.E. Giller. 2013. When yield gaps are poverty traps: The paradigm of ecological intensification in African smallholder agriculture. Field Crops Res. 143:76-90, https://doi.org/ 10.1016/j.fcr.2012.10.007.

Vandeplas, I., B. Vanlauwe, L. Driessens, R. Merckx and J. Deckers. 2010. Reducing labour and input costs in soybean by smallholder farmers in south-western Kenya. Field Crops Research 117:70-80, https://doi.org/10.1016/j. fcr.2010.02.002

von Liebig, J.F. 1840. Chemistry in its Application to Agriculture and Physiology. Taylor and Walton, London, UK.

Wang, N.N., H.H. He, C. Lacroix, C. Morris, Z.D. Liu, and F.W. Ma. 2019. Soil fertility, leaf nutrients and their relationship in kiwifruit orchards of China's central Shaanxi province. Soil Sci. Plant Nutr. 65(4):369-376, https://doi. org/10.1080/00380768.2019.1624481.
Wang, N., W. Joost, and F.S. Zhang. 2016. Towards sustainable intensification of apple production in China - Yield gaps and nutrient use efficiency in apple farming systems. J. Integrative Agr. 15:716-725, https://doi.org/ 10.1016/S2095-3119(15)61099-1.

Weinbaum, S.A., R.S. Johnson, and M.D. Theodore. 1992. Causes and consequences of overfertilization in orchards. HortTechnology 2(1):112-121, https://doi.org/10.21273/horttech.2.1.112b.

Wu, H.Y., Y. Kong, Y.C. Yao, N.N. Bi, L.P. Qi, and Z.G. Fu. 2010. Effects of intercropping aromatic plants on soil microbial quantity and soil nutrients in pear orchard. Zhongguo Nong Ye Ke Xue 43(1):140-150 (in Chinese).

Zhang, D., C. Wang, X.L. Li, X.S. Yang, L.B. Zhao, and S.J. Xia. 2019a. Correlation of production constraints with the yield gap of apple cropping systems in Luochuan County, China. J. Integr. Agr. 18(8):1714-1725, https://doi.org/ 10.1016/s2095-3119(18)62098-2.

Zhang, D., C. Wang, and X.L. Li. 2019b. Yield gap and production constraints of mango (Mangifera indica) cropping systems in Tianyang County, China. J. Integr. Agr. 18(8):17261736, https://doi.org/10.1016/s2095-3119(18) 62099-4.

Zhang, W.F., G.X. Cao, X.L. Li, H.Y. Zhang, C. Wang, Q. Liu, X.P. Chen, Z.L. Cui, J.B. Shen, R.F. Jiang, G.H. Mi, Y.X. Miao, F.S. Zhang, and Z.X. Dou. 2016. Closing yield gaps in China by empowering smallholder farmers. Nature 537: 671-674, https://doi.org/10.1038/nature19368.

Zhang, Y.C., H.M. Lei, W.G. Zhao, Y.J. Shen, and D.P. Xiao. 2018. Comparison of the water budget for the typical cropland and pear orchard ecosystems in the north China plain. Agr. Water Mgt. 198:53-64, https://doi.org/10.1016/j.agwat. 2017.12.027.

Zhou, G.F., S.A. Peng, Y.Z. Liu, Q.J. Wei, J. Han, and M.Z. Islam. 2014. The physiological and nutritional responses of seven different citrus rootstock seedlings to boron deficiency. Trees (Berl.) 28:295-307, https://doi.org/10.1007/ s00468-013-0949-y.

Zhu, L.W., X.M. Tang, T.Y. Lin, S.S. Zhou, P. Liu, Z.F. Ye, D.S. Wang, and Z.Y. Wu. 2017. First report of Fusarium root rot in Asian pear caused by Fusarium solani in China. Plant Dis. 101(1):252, https://doi.org/10.1094/pdis-07-160998-pdn. 